\title{
Lateral Lumbar Interbody Fusion and in Situ Screw Fixation for Rostral Adjacent Segment Stenosis of the Lumbar Spine
}

Young Hoon Choi, M.D., ${ }^{1}$ Shin Won Kwon, M.D., ${ }^{1}$ Jung Hyeon Moon, M.D., ${ }^{1,2}$ Chi Heon Kim, M.D., Ph.D., ${ }^{1,3,4}$ Chun Kee Chung, M.D., Ph.D., ${ }^{1,3,4,5}$ Sung Bae Park, M.D., ${ }^{6}$ Won Heo, M.D. ${ }^{1,7}$

Department of Neurosurgery, Seoul National University Hospital, Seoul, Korea

Department of Neurosurgery, ${ }^{2}$ The Armed Forces Capital Hospital, Seongnam, Korea

Department of Neurosurgery, ${ }^{3}$ Seoul National University College of Medicine, Seoul, Korea

Clinical Research Institute, ${ }^{4}$ Seoul National University Hospital, Seoul, Korea

Department of Brain and Cognitive Sciences, ${ }^{5}$ Seoul National University College of Natural Sciences, Seoul, Korea

Department of Neurosurgery, ${ }^{6}$ Seoul National University Boramae Hospital, Seoul, Korea

Department of Neurosurgery, Gyeongsang National University Changwon Hospital, Changwon, Korea

Objective : The purpose of this study is to describe the detailed surgical technique and short-term clinical and radiological outcomes of lateral lumbar interbody fusion (LLIF) and in situ lateral screw fixation using a conventional minimally invasive screw fixation system (MISF) for revision surgery to treat rostral lumbar adjacent segment disease.

Methods : The medical and radiological records were retrospectively reviewed. The surgery was indicated in 10 consecutive patients with rostral adjacent segment stenosis and instability. After the insertion of the interbody cage, lateral screws were inserted into the cranial and caudal vertebra using the MISF through the same LLIF trajectory. The radiological and clinical outcomes were assessed preoperatively and at $1,3,6$, and 12 months postoperatively.

Results : The median follow-up period was 13 months (range, 3-48 months). Transient sensory changes in the left anterior thigh occurred in 3 patients, and 1 patient experienced subjective weakness; however, these symptoms normalized within 1 week. Back and leg pain were significantly improved $(p<0.05)$. In the radiological analysis, both the segmental angle at the operated segment and anterior disc height were significantly increased. At 6 months postoperatively, solid bony fusion was confirmed in 7 patients. Subsidence and mechanical failure did not occur in any patients.

Conclusion : This study demonstrates that LLIF and in situ lateral screw fixation may be an alternative surgical option for rostral lumbar adjacent segment disease.

Key Words : Spinal fusion · Spinal stenosis · Minimally invasive surgical procedures · Reoperation.

- Received : June 7, 2017 •Revised : August 9, 2017 •Accepted : August 21, 2017

- Address for reprints : Jung Hyeon Moon, M.D.

Department of Neurosurgery, The Armed Forces Capital Hospital, 81 Saemaeul-ro 177beon-gil, Bundang-gu, Seongnam 13574, Korea Tel : +82-31-725-6234, Fax : +82-2-744-8459, E-mail : ucallitlove1004@hanmail.net

This is an Open Access article distributed under the terms of the Creative Commons Attribution Non-Commercial License (http://creativecommons.org/licenses/by-nc/4.0) which permits unrestricted non-commercial use, distribution, and reproduction in any medium, provided the original work is properly cited. 


\section{INTRODUCTION}

Spinal arthrodesis is a common surgical technique for degenerative lumbar spinal disease ${ }^{5,24,39)}$. However, reoperation and fusion are sometimes necessary due to the progression of degeneration at a rostral or caudal segment adjacent to a previous spinal arthrodesis ${ }^{2,6,27,30,32)}$. Typically, posterior decompression and/or fusion surgery are performed; however, reopening the previous operative site and dissecting through the scar tissue and around neural tissues are demanding surgical procedures ${ }^{7,11}$. By utilizing a retroperitoneal approach, those challenges may be obviated ${ }^{14)}$. Indirect decompression and effective lumbar lordosis may be achieved with the insertion of a large interbody cage using a retroperitoneal route ${ }^{18,29)}$. Currently, lateral lumbar interbody fusion (LLIF) is feasible due to improvements in surgical techniques and instruments ${ }^{14)}$. However, the use of a stand-alone cage leads to subsidence and non-union in approximately $30 \%$ of patients ${ }^{1,23,34,37)}$. Therefore, changes in the positioning and posterior instrumentation are necessary to prevent such complications. Moreover, the extension of the pedicle screw fixation requires the extension of the surgical field through the previous surgical site. The application of lateral screw fixation through the same LLIF trajectory may be an alternative to minimize the need for revision surger $\mathrm{y}^{25,31,36)}$. We have utilized a minimally invasive screw fixation system (MISF) to perform lateral screw fixation after LLIF to treat rostral lumbar adjacent segment degeneration (ASD). The objectives of the present study were to describe the detailed surgical technique and the short-term clinical and radiological outcomes.

\section{MATERIALS AND METHODS}

Patient medical and radiological records were retrospectively reviewed. Surgery was indicated for patients with intractable back and leg pain aggravated by walking and improved by sitting/lying down, irrespective of the use of various non-surgical management for more than 6 months, due to adjacent segment stenosis and instability after a previous arthrodesis. All patients had undergone posterior single- or two-level arthrodesis from L3 to S1, and solid arthrodesis at the previously operated site was confirmed by computed tomography (CT) and dynamic plain lateral X-rays. Radiological instability was observed in all patients at the adjacent level (more than $10^{\circ}$ of motion on flexion/extension radiographs or $4 \mathrm{~mm}$ of translation ${ }^{22)}$. Patients with osteoporosis and severe deformity according to the Scoliosis Research Society-Schwab Adult Spinal Deformity Classification, coronal deformity, $>20^{\circ}$ mismatch between pelvic incidence and lumbar lordosis, $>9.5 \mathrm{~cm}$ sagittal vertical axis and $>30^{\circ}$ pelvic tilt were not considered for this surgery ${ }^{35)}$. The surgery was performed in 10 consecutive patients from December 2012 to August 2016 (Table 1).

\section{Clinical and radiological assessments}

The clinical assessments were performed using patient-reported outcome questionnaires, including a Korean version of the Oswestry Disability Index (K-ODI, /45) ${ }^{21)}$ and a visual analogue pain score for the back $(/ 10)$ and leg $(/ 10)^{16,18)}$. All patients were encouraged to ambulate from the day of surgery using a lumbar brace, and patients were discharged on postoperative

Table 1. Demographics

\begin{tabular}{lc}
\hline Contents & Value \\
\hline Age (years) & $66 \pm 8$ \\
Gender (M : F) & $5: 5$ \\
Previous arthrodesis & \\
$\quad$ L3-5 & 3 \\
$\quad$ L4-S1 & 4 \\
L4-5 & 3 \\
K-ODI (/45) & $27 \pm 5$ \\
VAS-B $(/ 10)$ & $8 \pm 2$ \\
VAS-L $(/ 10)$ & $7 \pm 2$ \\
SVA (mm) & $35.7 \pm 52.9$ \\
LL ( $\left.{ }^{\circ}\right)$ & $-38.1 \pm 14.5$ \\
TK $\left(^{\circ}\right)$ & $21.2 \pm 9.5$ \\
\hline SA $\left(^{\circ}\right)$ & $-6.9 \pm 4.3$ \\
AH (mm) & $7.8 \pm 2.1$ \\
PH (mm) & $4.3 \pm 1.6$ \\
Pelvic tilt $\left(^{\circ}\right)$ & $21.4 \pm 8.6$ \\
Sacral slope $\left(^{\circ}\right)$ & $30.5 \pm 8.5$ \\
Pelvic incidence $\left(^{\circ}\right)$ & $51.9 \pm 8.1$ \\
\hline Values are presented & \\
\hline
\end{tabular}

Values are presented as mean \pm standard deviation. $M$ : male, $F$ : female, K-ODI : Korean Oswestry Disability Index, VAS-B : visual analogue pain score back, VAS-L : visual analogue pain score on leg, SVA : sagittal vertical axis, LL : lumbar lordosis, TK : thoracic kyphosis, SA : segmental angle, $\mathrm{AH}$ : anterior disc height, $\mathrm{PH}$ : posterior disc height 
day 3. All patients were scheduled for follow-up visits at 1, 3, 6, and 12 months after the surgery and yearly, thereafter. The median follow-up period was 13 months (range, 3-48 months). Preoperative imaging included magnetic resonance (MR) imaging, a CT scan and plain radiographs (standing anteriorposterior, lateral neutral, lateral flexion, lateral extension view of the lumbar spine and anterior-posterior/lateral 36-inch whole spine radiographs). The same questionnaires were administered, and plain radiographs were obtained at each follow-up visit. A CT scan was performed at 6 months after the surgery and was repeated at 12 months postoperatively if solid bony fusion had not occurred.

The radiological analysis included pelvic parameters (pelvic incidence, pelvic tilt, sacral slope), the sagittal vertical axis (SVA) from the center of $\mathrm{C} 7$ to the posterior corner of S1, lumbar lordosis (LL) from T12 to S1, and thoracic kyphosis (TK) from $\mathrm{T} 5$ to $\mathrm{T} 12$ on the whole spine X-rays (Fig. 1A $)^{17)}$. The segmental angle (SA), anterior disc height (AH), and posterior disc height $(\mathrm{PH})$ at the index level were measured using the lumbar X-rays (Fig. 1B). Solid fusion was defined as less than $5^{\circ}$ of motion and $1 \mathrm{~mm}$ of translation on the dynamic X-rays and the presence of bony bridging on CT images ${ }^{4,5,9)}$. Subsidence of the cage was defined as greater than a $2-\mathrm{mm}$ encroachment of the interbody cage into the vertebral endplate on the plain X-ray images and/or CT scan. The measurements were performed using $150 \%$ magnified images, to ensure high measurement reliability ${ }^{33}$, and the tools of the picture archiving and communication system (Marosis, version 5483; Infinitt Healthcare, Seoul, Korea), which is compatible with Microsoft Windows (Microsoft Corp., Redmond, WA, USA $)^{3,8)}$. Two researchers who were blinded to the patient information performed each measurement, and inter-observer variability was assessed using intraclass correlation coefficients (ICCs). The Institutional Review Board (H 1608-093735) approved our study.

\section{Surgical technique}

The surgery was divided into two steps : interbody cage insertion and lateral screw fixation. The basic surgical technique and instruments have been described previously ${ }^{14,28)}$. Under general anesthesia, the patient was placed in a true $90^{\circ}$ right lateral decubitus position with a rolled towel under the right flank and secured in this position with tape. A modular table system (Mizuho OSI Modular Table System, Mizuho,

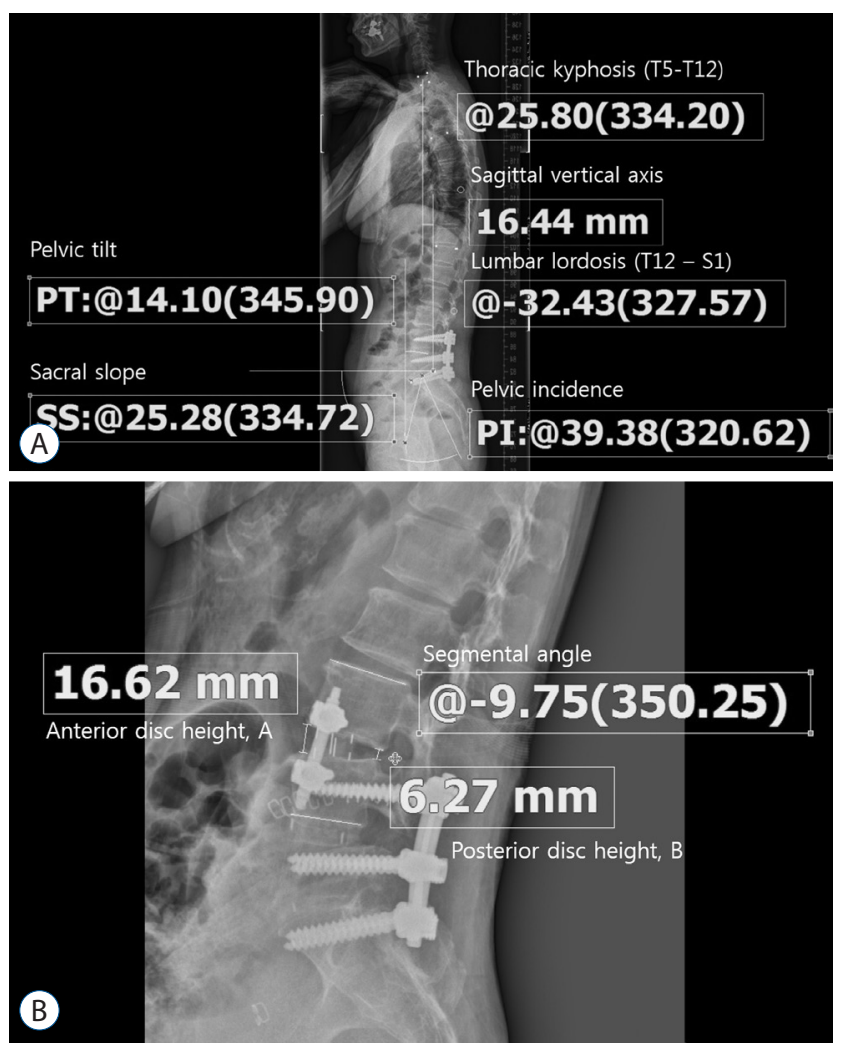

Fig. 1. Radiological measurements. $A$ : The sagittal vertical axis (SVA) is the horizontal distance from the $\mathrm{C7}$ plumb line to the posterior-superior corner of S1. Lumbar curvature (LL) and thoracic kyphosis (TK) were measured between the superior endplate of T12 and S1 and between T5 and T12, respectively, via Cobb's method using whole spine latera radiographs. Pelvic parameters were measured using the measurement tools included in the picture archiving and communication system. B : The segmental angle (SA) was measured between the superior endplates of the fused segment via Cobb's method. The anterior disc height $(A)$ and the posterior disc height $(B)$ on plain radiographs were measured to calculate the actual anterior $(\mathrm{AH})$ and posterior disc height $(\mathrm{PH})$. The length of the superior endplate of the $L 5$ vertebra was measured on the plain radiographs $(C)$ and computed tomography scans $\left(C^{\prime}\right)$. The actual length of the anterior disc and the posterior disc were calculated using the following formula : $\mathrm{AH}=\mathrm{A} \times\left(\mathrm{C}^{\prime} / \mathrm{C}\right) ; \mathrm{PH}=\mathrm{B} \times\left(\mathrm{C}^{\prime} / \mathrm{C}\right)$. $\mathrm{PI}$ : pelvic incidence, SS : sacral slope, PT : pelvic tilt.

CA, USA) was used, and the table was not flexed, similar to the oblique lumbar interbody fusion technique ${ }^{14)}$. A $5-\mathrm{cm}$ skin incision was made at the index level under fluoroscopic guidance. A probe was inserted at the anterior one-third of the disc space for stimulated electromyographic monitoring $\left(\mathrm{NIM}^{\circledR}\right.$ X-PAK; Medtronic, Memphis, TN, USA). The probe was passed into the disc space through or anterior to the psoas muscle. After the confirmation of the location of the probe, serial dilators and tubular retractors were introduced. A dis- 
cectomy was performed under direct vision using forceps, Cobb elevators and curettes. The size of the interbody cage was determined after the serial insertion of trial cages, and a permanent interbody cage that had been filled with allograft was implanted.

The second step consisted of the insertion of the lateral screws and rod through the same LLIF trajectory. MISFs were utilized to insert the lateral screws (Viper II ${ }^{\circledR}$; Depuy Synthes, Arlington, CA, USA or Longitude ${ }^{\circledR}$; Medtronic). The screw lengths were determined using the preoperative CT scans, and the screws were designed to reach the contralateral vertebral cortex. The tubular retractor was distracted, and a pilot hole with a tapper was made after an initial pilot hole had been constructed using a 16-G bone biopsy needle and guide wire (Fig. 2A, B) on one side. The segmental artery was coagulated and ligated under direct vision before creating the pilot hole, if necessary. The screws were inserted along the pilot hole via the MISF (Fig. 2C). In the other vertebra, the pilot hole was made as previously described or the hole produced by the stability pin was utilized. After the insertion of the guide wire through the hole, the screw was tapped and inserted. The rod insertion, application of the set screws, compression of the screws, and final securing of the set screws were sequentially performed via the percutaneous screw fixation system (Fig. 2D).

\section{Statistical analysis}

Clinical parameters were compared between the preoperative values and those obtained at the last follow-up visit using the Wilcoxon signed-rank test. Radiological parameters were compared using a linear mixed-effect model, which represents correlations among repeated measures from a subject, and this model was used to assess the longitudinal changes in LL,
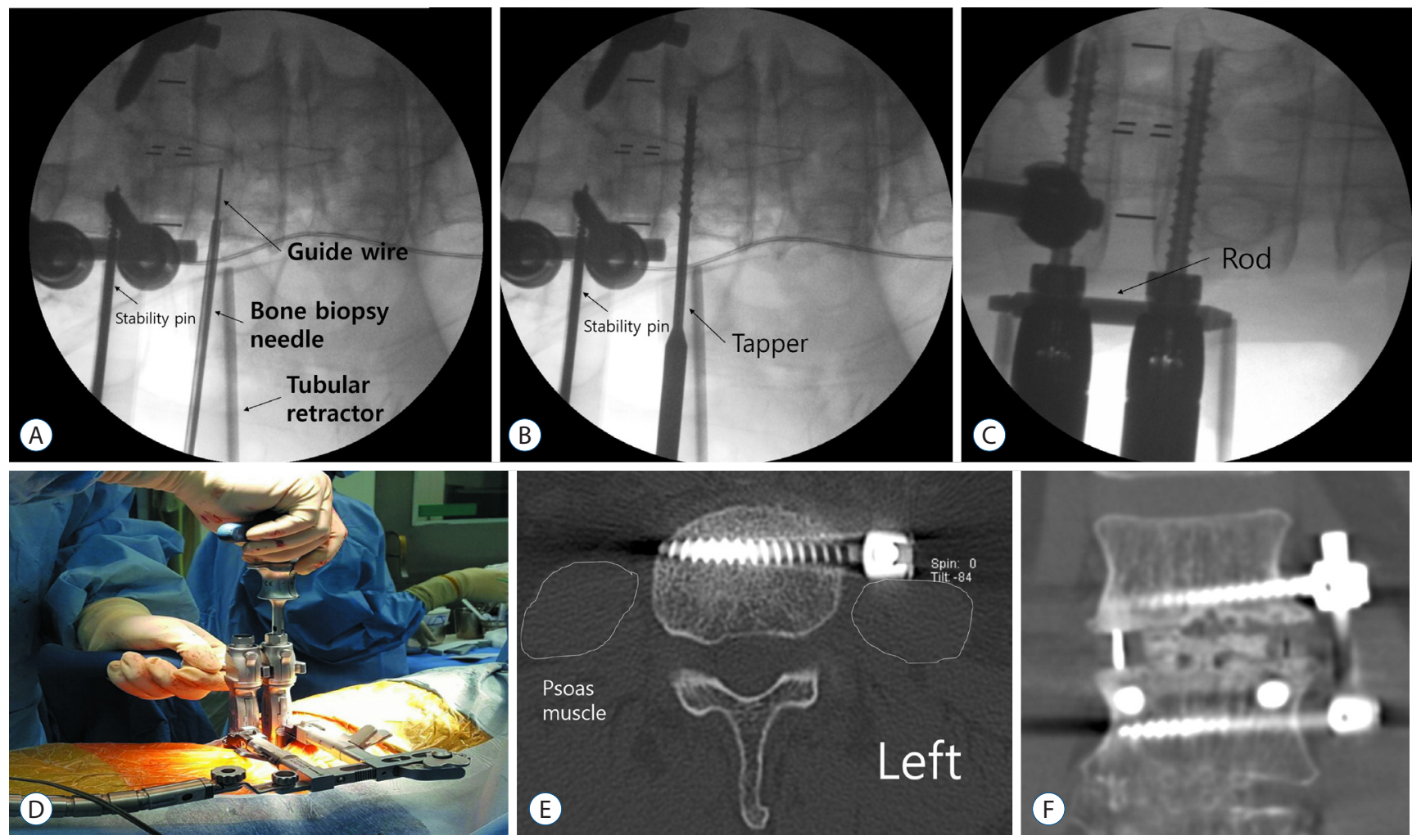

Fig. 2. Surgical procedures. A : An intraoperative fluoroscopic image shows that the bone biopsy needle is inserted into the rostral vertebra, and a guide wire is inserted along the needle. The radiolucent tubular retractor shows that the procedure was performed along the same trajectory as the lateral lumbar interbody fusion. B : The pilot hole was constructed using a tapper along the guide wire. The second pilot hole in the caudal vertebra was made after the insertion of the guide wire through the hole created by the stability pin. C : Insertion of screws/rod. D : Assembly of set screws, compression of the screws and final tightening may be facilitated using a percutaneous pedicle screw fixation system. E : The screw was inserted from the left side in the anterior $1 / 3$ of the vertebra, and the distal end reached the contralateral vertebral cortex. The screw was inserted anterior to the psoas muscle (white line) in this example. $\mathrm{F}$ : Solid bony fusion occurred at 6 months postoperatively. Note the location of the lateral screws. 
TK, SVA, SA, AH, and PH during the 12-month postoperative period. The fixed effect was time, and the random effect was subjects. Post hoc analysis was not planned due to the small number of patients. Statistical analyses were performed using SPSS software for Windows (ver. 21.0; IBM Corp., Chicago, IL, USA). The results were considered statistically significant if $p<0.05$ (two-sided).

\section{RESULTS}

All patients were ambulatory upon discharge at 3 days after the surgery. The mean operation time was $81 \pm 14$ minutes (range, 65-109 minutes), and the blood loss volume was less than $50 \mathrm{~mL}$. The segmental artery was ligated intraoperatively in 2 patients. Transient sensory changes in the left anterior thigh occurred in 3 patients, and 1 patient experienced subjective weakness, all of which normalized within 1 week postoperatively. Back pain and leg pain were significantly improved after the operation from $8 \pm 2$ and $7 \pm 2$ to $5 \pm 3$ and $4 \pm 2$, respectively, on the VAS ( $p=0.04$ and 0.02 ). The K-ODI decreased from $27 \pm 5$ to $21 \pm 7$ and showed a trend toward improvement $(p=0.09)$. The ICCs showed satisfactory correlation $(>0.9)$ for all radiological measurements except $\mathrm{pH}$ (0.72), and the mean values of each parameter were used in the present analysis. Two radiological parameters, SA and $\mathrm{AH}$, changed significantly with time ( $p=0.002$ and 0.011 , re-

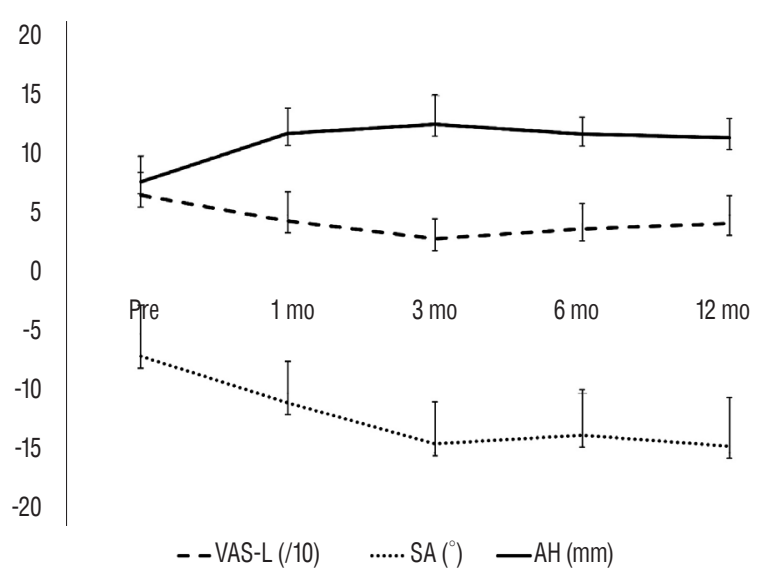

Fig. 3. Changes in leg pain and radiological parameters. The graphs show that during the first 3 postoperative months, leg pain decreased, and the segmental angle (SA) and anterior disc height (AH) increased. Radiological changes were not evident thereafter. mo : month, VAS-L : visual analogue pain score for the leg. spectively) according to the linear mixed-effect model, whereas the other factors did not show significant changes $(p>0.05)$ (Fig. 3). SA and AH mostly changed during the first 3 postoperative months and stabilized thereafter (Fig. 3). Mechanical failure did not occur in any patients (Fig. 2E), and no cases of subsidence were observed. CT scans were obtained in 9 patients at 6 months postoperative, and solid bony fusion was confirmed in 7 patients (Fig. 2F). According to X-rays, 9 patients met the fusion criteria, without mechanical failure or subsidence. Those results may indicate sufficient stability of the lateral screws.

\section{DISCUSSION}

The objectives of the present study were to describe the detailed surgical technique and determine the clinical and radiological outcomes utilizing LLIF and in situ screw fixation for rostral adjacent segment stenosis of the lumbar spine. The surgeries lasted approximately 80 minutes, and the patients had minimal bleeding. After the surgery, leg and back pain improved. The radiological findings showed that the SA and AH were significantly improved during the first 3 postoperative months without significant changes in the global spinal alignment.

\section{Adjacent segment degeneration and surgical techniques}

Due to the advancement of spinal instrumentation and surgical skills, the number of spinal fusion surgeries appears to be increasing ${ }^{10)}$. The posterior fixation approach to lumbar fusion may increase stresses at the adjacent facet joint and promote degeneration, particularly at the rostral adjacent segment $^{27)}$. Symptomatic ASD, which is unresponsive to nonsurgical treatment, requires reoperation. However, reoperation through a pre-existing surgical site is a demanding procedure. Although conventional revision surgery is performed posteriorly, it presents challenges such as a longer operative time, adhesions around the neural tissues and the risk of cerebrospinal fluid leakage ${ }^{7,13)}$. Additionally, the extension of the rod to the newly inserted pedicle screw requires further opening of the previous surgical site ${ }^{7,11}$ and sometimes necessitates the opening of the entire previously operated site. Nonetheless, a strong advantage of conventional open surgery was the clear docu- 
mentation of decompression under direct vision. Currently, direct decompression is possible with minimally invasive fusion surgeries such as transforaminal lumbar interbody fusion (TLIF), which is also another effective option ${ }^{38)}$.

Currently, LLIF is feasible due to improvements in surgical techniques and instruments ${ }^{14)}$. By circumventing the surgical route of the previous operation, the difficulties associated with scar tissue and adhesions may be avoided ${ }^{14,20,26,36)}$. Effective restoration of disc height and lordosis may be obtained via the insertion of a large-sized cage using the retroperitoneal route, and indirect decompression through ligamentotaxis may be achieved ${ }^{12,14,26,36)}$. Previous literature has shown that the dural sac was increased approximately 130-140\% compared to the preoperative value after direct lateral interbody fusion (DLIF) ${ }^{12,14)}$. However, the use of a stand-alone cage was associated with a high risk of subsidence and non-union in up to $30 \%$ of patients ${ }^{1,23,34,37)}$. Therefore, the use of instrumentation to prevent subsidence may be necessary. Instrumentation may be applied posteriorly by connecting to the previous rods using rod connectors. However, this technique required changing the patient position and reopening the previous scar, leading to a prolonged operative time. The use of instrumentation in the same position through the same skin incision may be desirable. Thus, a lateral plate and screw system may be utilized ${ }^{36)}$. In the present surgery, we utilized a conventional MISF. The conventional MISF is easy to use and familiar to many surgeons ${ }^{19)}$. Moreover, rod insertion, the compression/ distraction of screws and the anti-torque final tightening of the set screws are possible within a small operative field. Typically, disc height asymmetry between both sides exists after the insertion of the interbody cage, and the sequential compression of screws after rod placement may be necessary to obtain symmetric disc height on both sides and to secure the cage to the vertebral endplate.

However, the use of one lateral screw in each vertebral body is insufficient to control rotation in the sagittal plane, contrary to the use of pedicle screws, although lateral bending may be controlled $^{25,31)}$. The present study showed that the SA and $\mathrm{AH}$ increased during the first 3 postoperative months, indicating that rotation was not completely controlled, although such changes did not occur thereafter. CT scans were obtained in 9 patients at 6 months postoperative, and solid bony fusion was confirmed in 7 patients (Fig. 2F). According to plain radiographs, 9 patients met the fusion criteria without mechanical failure or subsidence. These results may indicate sufficient stability of the lateral screws. Nonetheless, comparative studies with conventional surgeries and other minimally invasive surgeries such as TLIF are required to show the efficacy of the present surgical technique.

\section{Limitations}

The present study had several limitations. First, the results were obtained from a small number of patients and cannot be generalized to all patients. Second, in the present study, postoperative MR images were not routinely obtained, and decompression was not radiologically proven. Previous literature has shown an effective increase in the spinal canal with DLIF, but those data were obtained after the initial operation ${ }^{12,14)}$. However, in the case of ASD, severe degenerative changes such as severe spinal canal stenosis, disc space narrowing and ossification of the yellow ligament were frequently combined. Therefore, the effect of indirect decompression may be limited due to the characteristics of ASD. Without postoperative MR images, documentation of sufficient decompression was not possible, which is a major limitation of the present study. The present surgical technique may be applicable when the insertion of a large-sized cage is preferable due to ligamentotaxis. Third, to provide stability in every direction, three-column lumbar stabilization is necessary ${ }^{31)}$. Although a limitation of motion was possible with the lateral screw system, a biomechanical study showed that the stability was lower than that achieved with a pedicle screw system ${ }^{25,31)}$. Therefore, the present surgical technique may be applicable only for the treatment of select patients with minimal instability. Fourth, although no permanent complications occurred, chronic irritation of the psoas muscle and genitofemoral nerve by the screw may cause difficulties. Due to these limitations, we also suggest direct decompression using TLIF as a primary choice for ASD. Although, we did not recommend the present surgical technique as a primary option for ASD, the present study showed the feasibility of DLIF and lateral screws as a minimally invasive technique. Because the posterior spinal structure and pedicles were preserved, this surgical technique may not hamper further surgery. Use of DLIF and lateral screws for ASD may be considered when multiple degeneration is present in the other spinal levels, and further ASD and re-revision surgeries could be expected, due to a lack of trauma to the posterior spinal structures ${ }^{15)}$. A long-term follow-up study 
with a larger number of patients is required.

\section{CONCLUSION}

This study demonstrates that minimally invasive LLIF and screw fixation may be an alternative revision surgery option to treat rostral lumbar ADS. A long-term follow-up study with a larger number of patients is required.

\section{- Acknowledgements}

This study was supported by a grant from the Korea Health Technology R\&D Project through the Korea Health Industry Development Institute (KHIDI), funded by the Ministry of Health \& Welfare, Republic of Korea (HC15C1320). This study was also partially supported by Grant No. 0420163070 (20161063) from the Seoul National University Hospital. The coauthor (CHK) is a consultant for Richard Wolf $\mathrm{GmbH}$.

\section{References}

1. Ahmadian A, Bach K, Bolinger B, Malham GM, Okonkwo DO, Kanter $A S$, et al. : Stand-alone minimally invasive lateral lumbar interbody fusion: multicenter clinical outcomes. J Clin Neurosci 22 : 740-746, 2015

2. Aiki H, Ohwada O, Kobayashi H, Hayakawa M, Kawaguchi S, Takebayashi T, et al. : Adjacent segment stenosis after lumbar fusion requiring second operation. J Orthop Sci 10 : 490-495, 2005

3. Barrey C, Jund J, Noseda O, Roussouly P : Sagittal balance of the pelvisspine complex and lumbar degenerative diseases. A comparative study about 85 cases. Eur Spine J 16 : 1459-1467, 2007

4. Bridwell KH, Lenke LG, McEnery KW, Baldus C, Blanke K : Anterior fresh frozen structural allografts in the thoracic and lumbar spine: do they work if combined with posterior fusion and instrumentation in adult patients with kyphosis or anterior column defects? Spine (Phila Pa 1976) $20: 1410-1418,1995$

5. Bridwell KH, Sedgewick TA, O'Brien MF, Lenke LG, Baldus C : The role of fusion and instrumentation in the treatment of degenerative spondylolisthesis with spinal stenosis. J Spinal Disord 6 : 461-472, 1993

6. Cheh G, Bridwell KH, Lenke LG, Buchowski JM, Daubs MD, Kim Y, et al. : Adjacent segment disease followinglumbar/thoracolumbar fusion with pedicle screw instrumentation: a minimum 5-year follow-up. Spine (Phila Pa 1976) 32 : 2253-2257, 2007

7. Chen WJ, Lai PL, Niu CC, Chen LH, Fu TS, Wong CB : Surgical treatment of adjacent instability after lumbar spine fusion. Spine 26 : E519-E524, 2001
8. Cho MJ, Chung CK, Kim CH : Screw loosening and migration after dynesys implantation. Korean J Spine 9 : 300-303, 2012

9. Choudhri TF, Mummaneni PV, Dhall SS, Eck JC, Groff MW, Ghogawala Z, et al. : Guideline update for the performance of fusion procedures for degenerative disease of the lumbar spine. Part 4: radiographic assessment of fusion status. J Neurosurg Spine 21 : 23-30, 2014

10. Deyo RA, Mirza SK, Martin BI, Kreuter W, Goodman DC, Jarvik JG : Trends, major medical complications, and charges associated with surgery for lumbar spinal stenosis in older adults. JAMA 303 : 1259-1265, 2010

11. Eichholz KM, Ryken TC : Complications of revision spinal surgery. Neurosurg Focus $15: \mathrm{E} 1,2003$

12. Elowitz EH, Yanni DS, Chwajol M, Starke RM, Perin NI : Evaluation of indirect decompression of the lumbar spinal canal following minimally invasive lateral transpsoas interbody fusion: radiographic and outcome analysis. Minim Invasive Neurosurg 54 : 201-206, 2011

13. Fritsch EW, Heisel J, Rupp $S$ : The failed back surgery syndrome: reasons, intraoperative findings, and long-term results: a report of 182 operative treatments. Spine 21 : 626-633, 1996

14. Fujibayashi S, Hynes RA, Otsuki B, Kimura H, Takemoto M, Matsuda S: Effect of indirect neural decompression through oblique lateral interbody fusion for degenerative lumbar disease. Spine (Phila Pa 1976) 40 : E175-E182, 2015

15. Jagersberg M, Schneider $K$, Schaller C, Richter M : ALIF versus TLIF for post-discectomy syndrome. J Neurol Surg A Cent Eur Neurosurg $75: 329-335,2014$

16. Kim CH, Chung CK, Choi Y, Shin H, Woo JW, Kim SM, et al. : The usefulness of a mobile device-based system for patient-reported outcomes in a spine outpatient clinic. Spine J $16: 843-850,2016$

17. Kim CH, Chung CK, Hong HS, Kim EH, Kim MJ, Park BJ : Validation of a simple computerized tool for measuring spinal and pelvic parameters. J Neurosurg Spine 16 : 154-162, 2012

18. Kim CH, Chung CK, Park SB, Yang SH, Kim JH : A change in lumbar sagittal alignment after single-level anterior lumbar interbody fusion for lumbar degenerative spondylolisthesis with normal sagittal balance. Clin Spine Surg 30 : 291-296, 2016

19. Kim CH, Chung CK, Sohn S, Lee S, Park SB : Less invasive palliative surgery for spinal metastases. J Surg Oncol 108 : 499-503, 2013

20. Kim CH, Chung CK, Sohn S, Lee S, Park SB : The surgical outcome and the surgical strategy of percutaneous endoscopic discectomy for recurrent disk herniation. J Spinal Disord Tech 27 : 415-422, 2014

21. Kim DY, Lee SH, Lee HY, Lee HJ, Chang SB, Chung SK, et al. : Validation of the korean version of the oswestry disability index. Spine (Phila Pa 1976) 30 : E123-E127, 2005

22. Leone A, Guglielmi G, Cassar-Pullicino VN, Bonomo L : Lumbar intervertebral instability: a review. Radiology 245 : 62-77, 2007

23. Marchi L, Abdala N, Oliveira L, Amaral R, Coutinho E, Pimenta L : Radiographic and clinical evaluation of cage subsidence after stand-alone lateral interbody fusion. J Neurosurg Spine 19 : 110-118, 2013

24. Nachemson A, Zdeblick TA, O'Brien JP : Lumbar disc disease with discogenic pain. What surgical treatment is most effective? Spine (Phila Pa 
1976) $21:$ 1835-1838, 1996

25. Nayak AN, Gutierrez S, Billys JB, Santoni BG, Castellvi AE : Biomechanics of lateral plate and pedicle screw constructs in lumbar spines instrumented at two levels with laterally placed interbody cages. Spine J 13 : 1331-1338, 2013

26. Palejwala SK, Sheen WA, Walter CM, Dunn JH, Baaj AA : Minimally invasive lateral transpsoas interbody fusion using a stand-alone construct for the treatment of adjacent segment disease of the lumbar spine: review of the literature and report of three cases. Clin Neurol Neurosurg $124: 90-96,2014$

27. Park P, Garton HJ, Gala VC, Hoff JT, McGillicuddy JE : Adjacent segment disease after lumbar or lumbosacral fusion: review of the literature. Spine (Phila Pa 1976) 29 : 1938-1944, 2004

28. Park SJ, Lee CS, Chung SS, Kang SS, Park HJ, Kim SH : The ideal cage position for achieving both indirect neural decompression and segmental angle restoration in lateral lumbar interbody fusion (LLIF). Clin Spine Surg 30 : E784-E790, 2016

29. Phan K, Thayaparan GK, Mobbs RJ : Anterior lumbar interbody fusion versus transforaminal lumbar interbody fusion--systematic review and meta-analysis. Br J Neurosurg 29 : 705-711, 2015

30. Rahm MD, Hall BB : Adjacent-segment degeneration after lumbar fusion with instrumentation: a retrospective study. J Spinal Disord 9 : 392400, 1996

31. Reis MT, Reyes PM, Bse, Altun I, Newcomb AG, Singh V, et al. : Biomechanical evaluation of lateral lumbar interbody fusion with secondary augmentation. J Neurosurg Spine 25 : 720-726, 2016

32. Sears WR, Sergides IG, Kazemi N, Smith M, White GJ, Osburg B : In- cidence and prevalence of surgery at segments adjacent to a previous posterior lumbar arthrodesis. Spine J 11 : 11-20, 2011

33. Song KS, Piyaskulkaew C, Chuntarapas T, Buchowski JM, Kim HJ, Park MS, et al. : Dynamic radiographic criteria for detecting pseudarthrosis following anterior cervical arthrodesis. J Bone Joint Surg Am 96 : 557-563, 2014

34. Tempel ZJ, Gandhoke GS, Bolinger BD, Okonkwo DO, Kanter AS : Vertebral body fracture following stand-alone lateral lumbar interbody fusion (LLIF): report of two events out of 712 levels. Eur Spine J 24 Suppl 3 : 409-413, 2015

35. Terran J, Schwab F, Shaffrey Cl, Smith JS, Devos P, Ames CP, et al. : The SRS-Schwab adult spinal deformity classification: assessment and clinical correlations based on a prospective operative and nonoperative cohort. Neurosurgery 73 : 559-568, 2013

36. Wang MY, Vasudevan R, Mindea SA : Minimally invasive lateral interbody fusion for the treatment of rostral adjacent-segment lumbar degenerative stenosis without supplemental pedicle screw fixation. J Neurosurg Spine $21: 861-866,2014$

37. Watkins $R$ 4th, Watkins $R 3$ rd, Hanna $R$ : Non-union rate with standalone lateral lumbar interbody fusion. Medicine (Baltimore) 93 : e275, 2014

38. Yee TJ, Terman SW, La Marca F, Park P : Comparison of adjacent segment disease after minimally invasive or open transforaminal lumbar interbody fusion. J Clin Neurosci 21 : 1796-1801, 2014

39. Zdeblick TA : A prospective, randomized study of lumbar fusion: Priliminary Results. Spine (Phila Pa 1976) 18 : 983-991, 1993 